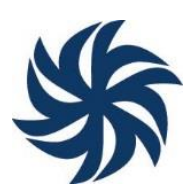

\title{
CRÍTICA À DOUTRINA DOS DIREITOS NATURAIS E INALIENÁVEIS ${ }^{1}$
} JEREMY BENTHAM

\section{CRITIQUE OF THE DOCTRINE OF INALIENABLE, NATURAL RIGHTS JEREMY BENTHAM}

\section{CRÍTICA A LA DOCTRINA DE DERECHOS NATURALES E INALIENABLES JEREMY BENTHAM}

Jeremy Bentham

Resumo: Texto clássico, no qual Jeremy Bentham faz um ataque veemente à Declaração dos Direitos do Homem e do Cidadão, em particular, e à existência de direitos naturais e fora do Estado, em específico. Trata-se de um dos elementos lógicos da proposta utilitarista, a de que o interesse público geral ou a maximização da felicidade e bem-estar de todos deve estar acima de outras considerações, tal como a noção da existência de direitos naturais. No presente, a mesma lógica é invocada quando se opõe o interesse público geral a propostas de eliminação ou redução de direitos sociais e econômicos da população.

Palavras-chave: Utilitarismo. Ética coletiva. Direitos naturais.

\begin{abstract}
A classical text, with a vehement attack of Jeremy Bentham on the Declaration of the Rights of Man and of the Citizen, in general, and to the notion of natural rights, out of the state, in particular. There is one of the logical elements of the utilitarian proposition, regarding the general public interest, or the maximization of happiness and well-being of all, as prior and more important than anything, including the notion of natural rights. Nowadays, the same logic is used when some governments try to oppose the general public interest to the need of eliminating or reducing social and economic rights of the population.
\end{abstract}

Keywords: Utilitarism. Collective ethics. Natural rights.

Resumen: Texto clásico en el que Jeremy Bentham ataca con vehemencia la Declaración de los Derechos Humanos y de los Ciudadanos en particular y la existencia de los derechos naturales y no estatales en particular. Uno de los elementos lógicos de la propuesta utilitaria es que el interés público general o la maximización de la felicidad y el bienestar para todos deben estar por encima de otras consideraciones, como la noción de la existencia de los derechos naturales. En la actualidad, se invoca la misma lógica cuando el interés público general se opone a las propuestas para la eliminación o reducción de los derechos sociales y económicos de la población.

\footnotetext{
${ }^{1}$ Traduzido a partir do original em inglês disponível em https://oll.libertyfund.org/titles/bentham-the-works-of-jeremybentham-vol-2. Texto em domínio público e com reprodução expressamente autorizada pelo site para fins acadêmicos e educacionais. O texto faz parte da 'Online Library of Liberty', uma coleção de trabalhos acadêmicos sobre liberdade individual e mercados livres. O trecho em questão é extraído da obra: BENTHAM, Jeremy. Anarchical Fallacies. Londres: Bowring, 1843. v. 2.
} 
Palabras clave: Utilitarismo. Ética colectiva. Derechos naturales

\section{Comentário do Tradutor ${ }^{2}$}

Jeremy Bentham fez um ataque veemente e virulento à Declaração dos Direitos do Homem e do Cidadão, imputando-a com as pechas de filosoficamente débil, logicamente inconsistente, verbalmente equivocada e ineficaz na prática. Trata-se de um fragmento de sua obra, que precisa ser contextualizada e explorada em mais profundidade, dadas as ricas interpretações e extrapolações que podem ser feitas a partir do seu texto.

O propósito da presente tradução é disponibilizar esse texto em português, justamente com o objetivo de convidar mais análises e reflexões em nossa língua materna. O momento, todavia, também é elemento oportuno a sinalizar a validade de se pensar a partir dos elementos avançados no pensamento de Bentham.

O repúdio radical à proposição de direitos que seriam naturais e imprescritíveis, de um modo específico, e ao jusnaturalismo, no geral, relaciona-se diretamente à assunção da premissa de que a utilidade deveria ser o critério último em todas as questões éticas, que, por sua vez, está na raiz do pensamento utilitarista. Para Bentham, o governo teria como finalidade alcançar o máximo de felicidade para o máximo possível de pessoas, e não a de reconhecer direitos individuais.

Adotar o conceito de utilidade como único filtro para os direitos individuais a serem criados e mantidos, associado à visão legalista sobre direitos - não há direitos sem a lei, não há direitos contra a lei e não há direitos anteriores à lei - é o mantra de Bentham. O tema torna-se pertinente em um momento em que o Estado ameaça os direitos individuais, sociais e econômicos, invocando o 'interesse público geral', apenas outra forma de expressar o princípio da utilidade. No altar dos austericidas, sacrificam-se direitos sociais e econômicos em nome da sobrevivência financeira do Estado.

Similarmente, também se reivindica um suposto 'interesse público geral' para retirar direitos de expressão, censurar obras e praticar políticas públicas de desconstrução do arcabouço institucional—democrático de preservação das minorias. Talvez essa chave explique, ao menos parcialmente, a conjugação entre o pensamento reacionário e o ideário econômico liberal que obteve êxito nas últimas eleições nacionais.

\section{Observações Preliminares}

A Declaração dos Direitos - refiro-me ao documento publicado com esse nome pela Assembleia Nacional Francesa em 1791 - assume como seu escopo um campo de dissertação tão

\footnotetext{
${ }^{2}$ Traduzido pelo Prof. Dr. André Rehbein Sathler Guimarães, docente do Mestrado em Poder Legislativo do Centro de Formação, Treinamento e Aperfeiçoamento da Câmara dos Deputados.
} 
ilimitado, em termos de sua extensão, quanto importante em termos de sua natureza. Mas, quanto mais ampla é a extensão dada a qualquer proposição ou cadeia de proposições, mais difícil é manter confinada a importância delas, sem derivações, dentro dos limites da verdade e da razão. Se em algum dos menores cantos do campo sobre o que se debruça há uma falha em coincidir com a rígida linha da retidão, não tarda a que a aberração seja apontada, que (assim como não há média entre a verdade e a falsidade) se deixem as pretensões de apelação ao truísmo e quem quer que seja que analise o assunto precisa reconhecer que é falso e errôneo, e se, como aqui, a conduta política é o tema, é mais pernicioso ainda que o erro perdure e não seja detectado.

Em um trabalho de tão extrema importância e com um viés para a prática, e que, consequentemente, mantenha a prática tão perto e imediatamente próxima, professadamente como objetivo em vista, um único erro pode ser acompanhado das consequências mais fatais. Quanto mais extensivas forem as proposições, mais consumado será o conhecimento, mais requintada a habilidade indispensavelmente necessária para confiná-las, em todos os seus pontos, aos limites da verdade. A mais consumada habilidade em toda a nação poderia não ser suficiente para a tarefa - pode-se arriscar a dizer, que essa habilidade não teria se igualado à tarefa. Mas que, na sanção de cada proposição, a mais consumada habilidade aconteça de estar estabelecida nas cabeças da pobre maioria em cujas mãos a plenitude do poder aconteça de estar investida na mesma ocasião, é um evento contra o qual as chances são quase que como do infinito contra um.

Aqui, então, há um erro radical e onipresente - a tentativa de dar a um trabalho sobre esse assunto a sanção do governo; especialmente de um tal governo - um governo composto de membros tão numerosos, tão desiguais em talento, quanto discordantes em inclinações e interesses. Caso tivesse sido o trabalho de uma única mão, de um particular, e sob essa condição fosse dada ao mundo, teria produzido todos os bons efeitos que poderia produzir tendo sido publicada como obra do governo, sem ter nenhum dos maus efeitos que, no caso de pequenos erros, poderiam resultar dele, uma vez publicado como um trabalho do governo.

Tendo a revolução que jogou o governo nas mãos dos escritores e adotantes dessa declaração sido efeito de insurreição, seu grande objetivo, evidentemente, é justificar a causa. Mas, ao justificá-la, eles a convidam: ao justificar insurreições no passado eles plantam e cultivam a propensão para perpétua insurreição no futuro; eles lançam as sementes da disseminação da anarquia: ao justificar a demolição das autoridades existentes, eles minam todas as futuras, a deles próprios, por consequência. Vaidade superficial e imprudente! Eles imitam em sua conduta o autor daquela lendária lei segundo a qual o assassinato do príncipe no trono dava ao assassino o direito de sucedê-lo. "Pessoas, eis os seus direitos!" Se um único artigo deles for violado, a insurreição não é apenas seu direito, mas um de seus mais sagrados deveres". Essa é a linguagem constante, pois tal é o objeto professo dessa fonte e modelo de todas as leis - esse autoconsagrado oráculo de todas as nações...

Os grandes inimigos da paz pública são o egoísmo e as paixões antisociais: - necessárias 
como eles são - um para a própria existência de cada indivíduo, as outras, para a sua segurança. Da parte desses interesses, uma fraqueza em um ponto de força não deve nunca ser apreendida: tudo o que é para ser apreendido com respeito a eles é para ser apreendido pelo lado de seu excesso. A sociedade é mantida unida apenas pelos sacrifícios que os homens podem ser induzidos a fazer em detrimento das gratificações que eles demandam: obter esses sacrifícios é a grande dificuldade, a maior tarefa do governo. Qual tem sido o objeto, o perpétuo e palpável objeto, dessa declaração de pretensos direitos? Acrescentar tanta força quanto possível a essas paixões, que já eram muito fortes, - para arrebentar as cordas que as mantém presas, - para dizer às paixões egoístas, ali - em qualquer lugar - está a sua presa! - para as paixões raivosas, ali em qualquer lugar - está o seu inimigo.

Essa é a moralidade desse célebre manifesto, tornado famoso pelas mesmas qualidades que deram celebridade ao incendiário do tempo de Efésios.

A lógica dele está em uníssono com a sua moralidade: - uma veia perpétua de nonsense, fluindo de um abuso perpétuo das palavras, - palavras com sentidos variados, quando havia igualmente à disposição palavras com sentido único - as mesmas palavras usadas com sentidos diferentes na mesma página, - palavras usadas com sentidos diferentes do que significam propriamente, quando palavras com sentidos próprios estavam igualmente a mão, - palavras e proposições de significações as mais amplas possíveis, soltas, sem nenhuma dessas exceções ou modificações que são tão necessárias em cada ocasião para reduzir seu significado ao compasso, não apenas da correta razão, mas ainda da concepção que se tem em mãos, seja qual for a sua natureza; - a mesma falta de acurácia, a mesma desatenção na redação desse aglomerado de verdades sobre o qual o destino das nações estava pendurado, como se fosse um conto oriental, ou uma alegoria para uma revista: - epigramas obsoletos, ao invés das distinções necessárias, expressões figurativas preferidas às mais simples, - presunções sentimentais, tão triviais quanto sem sentido, preferidos às expressões aptas e precisas, - ornamentos escorregadios preferidos à majestosa simplicidade do sonoro bom senso, - e os atos do conselho carregados e desfigurados pelos enfeites do teatro.

\section{Artigo II}

O fim em vista de cada associação política é a preservação dos direitos naturais e imprescritíveis do homem. Esses direitos são liberdade, propriedade, segurança e resistência à opressão.

Sentença 1. O fim em vista de cada associação política é a preservação dos direitos naturais e imprescritíveis do homem.

Mais confusão - mais nonsense, - e o nonsense, como usual, é nonsense perigoso. Dificilmente pode-se dizer que as palavras têm um significado: mas se têm, essas seriam as proposições afirmadas ou implicadas: 
1. Que existem tais coisas como direitos antes do estabelecimento dos governos: pois natural, aplicado a direitos, se significa alguma coisa, significa estar no sentido contrário de legal - e como esses direitos reconhecidamente devem a sua existência ao governo, consequentemente são posteriores em sua data de criação ao estabelecimento do governo.

2. Que esses direitos não podem ser revogados pelo governo: pois não podem está implícito na forma da palavra imprescritíveis, e o sentido do qual ela se reveste quando aplicada, é o sentido direto explicado acima.

3. Que os governos que existem derivam sua origem de associações formais ou o que agora é chamado de convenções: associações nas quais se entra por um contrato de parceria, com todos os seus membros como parceiros, - firmado em um dia prefixado, para um propósito predeterminado, a formação de um novo governo onde não havia nenhum anteriormente (porque o caso de reuniões formais mantidas sob o controle de um governo existente está evidentemente fora de questão aqui) o que parece novamente estar implicado no modo de inferência, apesar de uma necessária e inevitável inferência de que todos os governos (ou seja, autodenominados governos, nós de pessoas exercendo os poderes de governo) que tenham tido alguma outra origem que não uma associação conforme a descrição acima são ilegais, ou seja, não há nenhum governo em absoluto; resistência a eles e subversão deles é portanto lícito e louvável, e assim por diante.

Tais são as noções implicadas na primeira parte do artigo. Como fica a verdade das coisas? Não há tal coisa como direitos naturais - não há algo como direitos anteriormente ao estabelecimento do governo - não há algo como direitos naturais oponíveis a, em contraposição, aos direitos legais: essa expressão é tão somente figurativa; que, quando usada, no momento em que você tenta dar a ela um sentido literal, ela o leva ao erro, e ao tipo de erro que provoca danos - danos extremos.

Nós sabemos o que significa para o homem viver sem governo - e viver sem governo, viver sem direitos: nós sabemos o que significa para o homem viver sem governo, pois vemos exemplos desse modo de vida - vemos isso em muitas nações selvagens, ou melhor, em muitas raças da humanidade; por exemplo, entre os selvagens de New South Wales, cujo modo de vida é tão bem conhecido por nós: nenhum hábito de obediência e, portanto, nenhum governo nenhum governo, portanto nenhuma lei - nenhuma lei, portanto nada como direitos - nenhuma segurança - nenhuma propriedade: -- liberdade, contra o controle regular, o controle das leis e do governo - perfeito; mas contra todos os controles irregulares, os mandatos de indivíduos mais fortes, nenhuma liberdade. Nesse estado, em uma época anterior ao começo da história - nesse mesmo estado, a julgar pela analogia, nós, os habitantes dessa parte do globo que chamamos de Europa estávamos - nenhum governo, consequentemente nenhum direito: nenhum direito, consequentemente nenhuma propriedade - nenhuma segurança legal - nenhuma liberdade legal: não mais segurança do que a que pertencem às feras - previsão e sensação de insegurança mais aguda - consequentemente, em termos de felicidade, estávamos abaixo do nível da raça brutal. 
Em proporção à falta de felicidade resultante da falta de direitos, uma razão existe para que houvesse algo assim como direitos. Mas razões para desejar que existissem tais coisas como direitos não são direitos; - uma razão para desejar que um certo direito fosse estabelecido não é esse direito - querer não é ter - fome não é pão.

Aquilo que não tem existência não pode ser destruído - aquilo que não pode ser destruído não pode exigir nada para preservá-lo da destruição. Direitos naturais são simplesmente nonsense: direitos naturais e imprescritíveis, nonsense retórico, - nonsense sobre palafitas. Mas esse nonsense retórico termina na velha tradição das travessuras sem sentido, pois assim que uma lista desses pretensos direitos naturais é dada, vê-se que esses se apresentam como direitos legais. E entre esses direitos, sejam quais forem, não há, parece, nenhum que qualquer governo possa, em qualquer ocasião, revogar até a menor partícula.

Basta de linguagem terrorista. Qual é a linguagem da razão e do bom senso sobre o mesmo tema? Que, na proporção em que é certo e apropriado, i.e. vantajoso para a sociedade em questão, que esse ou aquele direito - um direito a esse ou aquele efeito - deve ser estabelecido e mantido, na mesma proporção é errado que ele seja revogado: mas não há direito que não deva ser mantido, enquanto for vantajoso para a sociedade como um todo que ele seja mantido, portanto não há direito que, quando a sua abolição for vantajosa para a sociedade, não deva ser abolido. Para saber se seria mais vantajoso para a sociedade que esse ou aquele direito seja mantido ou abolido, deve ser considerada a época em que a questão sobre a manutenção ou abolição é proposta, e as circunstâncias sob as quais se dá a proposta de manter ou abolir o direito; o direito em si mesmo deve ser especificamente descrito, não ser confundido com uma pilha indiscernível de outros, sob termos tão vagos como propriedade, liberdade e similares.

Uma coisa, no meio de todas essas confusões, é bastante clara. Eles não sabem do que estão falando debaixo do nome de direitos naturais, e ainda que eles os tenham feito imprescritíveis - à prova de todo o poder das leis - eles são prenhes de ocasiões de convocação dos membros da comunidade a se levantarem em resistência contra as leis. Qual era, então, o seu objetivo em declarar a existência de direitos imprescritíveis, sem especificar nenhum sequer com qualquer marca que pudesse ser reconhecida? Este e nenhum outro - excitar e manter um espírito de resistência a todas as leis - um espírito de insurreição contra todos os governos - contra os governos de todas as nações instantaneamente, - contra o governo de sua própria nação - contra o governo que eles mesmos estavam fingindo estabelecer - mesmo que com isso seu próprio reino deveria estar próximo do final. Em nós está a perfeição da virtude e da sabedoria: em todo o resto da humanidade, o extremo da maldade e da insensatez. Nossa vontade deve, consequentemente, reinar sem controle e para sempre: reinar agora enquanto vivemos - reinar após a nossa morte.

Todas as nações - de todas as futuras eras - devem ser, pois estão predestinadas a ser, nossos escravos.

Governos futuros não vão ter honestidade suficiente para merecerem confiança com a 
determinação de quais direitos devem ser mantidos, quais revogados - quais leis mantidas em vigor, quais abandonadas. Os futuros súditos (eu deveria dizer futuros cidadãos, por que o governo francês não admite súditos) não terão inteligência suficiente para merecerem confiança quanto a escolha de se submeter à determinação do governo de sua época ou de a ele resistir. Governos, cidadãos - até o final dos tempos - devem ser mantidos em cadeias.

Tais são as máximas - tais as premissas - porque apenas com essas premissas que a doutrina dos direitos imprescritíveis e das leis irrevogáveis pode ser mantida.

Qual é a verdadeira fonte desses direitos imprescritíveis - dessas leis irrevogáveis? O poder ficou cego ao olhar da sua própria altura: vaidade e tirania são exaltados até a insanidade. Nenhum homem deveria ter outro homem por servo, ainda que todos os homens sejam para sempre seus escravos. Fazendo leis com impostura em suas bocas, sob o pretexto de declará-las - dando para as leis tudo o que vem em primeiro lugar, e torná-las inafastáveis, sob o pretexto de encontrá-las prontas. Feitos pelo quê? Não por um Deus - eles não aceitam nenhum; mas por sua deusa, a natureza.

A origem dos governos a partir de um contrato é pura ficção ou, em outras palavras, uma falsidade. Nunca se soube ser verdade, em qualquer instância; a sua afirmação causa prejuízos, ao envolver o assunto em erro e confusão, e não é necessária nem útil para qualquer bom propósito.

Todos os governos de que temos algum registro foram estabelecidos gradualmente por hábito, após terem sido formados pela força; a não ser no caso dos governos formados por indivíduos que tenham sido emancipados, ou tenham emancipado a si mesmos, de governos já formados, os governos sob os quais eles nasceram - um caso raro, e do qual nada se segue com relação ao resto. O que significa perguntar como os governos são formados? É o menos apropriado - o menos propício para a felicidade da sociedade - que a felicidade da sociedade deva ser o único objetivo mantido em vista pelos membros do governo em todas as suas medidas? Quanto menor o interesse dos homens de serem felizes - menos se deseja que assim seja - menor o dever moral de seus governantes de fazê-los felizes, tanto quanto possam, tanto em Mogadore quanto em Filadélfia.

De onde é, senão do governo, que os contratos derivam sua força vinculante? Os contratos vieram do governo, não o governo dos contratos. É tão do hábito fazer cumprir os contratos, e vêlos cumpridos que os governos são em grande parte devedores por qualquer disposição que tenham para observá-los.

Sentença 2. Esses direitos [esses imprescritíveis tanto quanto naturais direitos], são liberdade, propriedade, segurança e resistência à opressão.

Observe a extensão desses pretensos direitos, cada um deles pertencente a todos os homens e todos eles sem limites. Liberdade ilimitada; isto é, entre outras coisas, a liberdade de fazer ou não fazer, em qualquer ocasião, aquilo que lhe agrada. Propriedade ilimitada; ou seja, o 
direito de fazer com qualquer coisa em seu entorno (com qualquer coisa, no mínimo, senão com qualquer pessoa), o que quer que lhe agrade. Comunicar esse direito a qualquer pessoa e retirá-lo de qualquer pessoa. Segurança ilimitada; ou seja, segurança para essa sua liberdade, para essa sua propriedade e para a sua pessoa, contra qualquer diminuição que possa ser demandada, sob qualquer título, a respeito dessas liberdades. Resistência ilimitada à opressão; ou seja, exercício ilimitado da faculdade de preservar a si mesmo contra quaisquer circunstâncias desagradáveis que possam se apresentar à sua imaginação ou às suas paixões sob aquele nome. Natureza, dizem alguns dos intérpretes da pretensa lei da natureza - a natureza dá a cada homem um direito a tudo; o que é, em efeito, apenas outra forma de dizer que a natureza não deu esse direito a ninguém; porque, com relação à maioria dos direitos, é verdade que o que é direito de todos os homens é o direito de nenhum dos homens; assim como o que é negócio de todos os homens não é negócio de nenhum homem. A natureza deu a cada homem um direito a tudo: se isso é verdadeiro, então os governos humanos e as leis humanas têm a necessidade de dar a cada homem o seu direito próprio, sem o que nenhum direito valeria alguma coisa. A natureza deu a cada homem um direito a tudo antes da existência das leis, e na falta de leis. Essa universalidade nominal, não essencial realmente, do direito, instituída provisoriamente pela natureza na ausência de leis, da qual o oráculo francês se apropria, e a perpetua sob a lei e a despeito das leis. Esses direitos anárquicos que a natureza instituiu, a arte democrática tenta fechar e declarar indefensáveis.

Liberdade ilimitada - eu preciso ainda dizer liberdade ilimitada; - porque o próximo artigo retorna à carga, e dá uma definição tal de liberdade que parece desejar estabelecer limites para ela, ainda que de fato a limitação não valha nada; e quando, como aqui, nenhum aviso é dado sobre alguma exceção na textura da regra geral, cada exceção que aparece é não uma confirmação mas uma contradição à regra: - liberdade, sem qualquer limite preanunciado ou inteligente; e quanto aos outros direitos, eles permanecem ilimitados até o fim: direitos do homem compostos de um sistema de contradições e impossibilidades.

Em vão dir-se-ia que, apesar de não ter sido atribuído nenhum limite a qualquer um desses direitos, ainda assim deve ser entendo e assumido como certo e tacitamente admitido e assumido que eles devem ter limites; viz. esses limites, como são compreendidos, serão estabelecidos pelas leis. Vã, eu digo, seria essa defesa; pois a suposição entraria em contradição com a declaração expressa pelo artigo em si próprio, e derrotaria o próprio objeto que a declaração como um todo tem em vista. Seria autocontraditório, porque, com o mesmo sopro com que a existência desses direitos é declarada, eles são declarados imprescritíveis; e imprescritível, ou como nós na Inglaterra costumamos dizer, irrevogáveis, não significa nada a menos que se considere a exclusão da interferência das leis.

Isso seria inconsistente não só consigo mesmo, mas também inconsistente com o objetivo único e declarado da declaração, se não fosse excluída a interferência das leis. É contra as próprias leis, e as leis apenas, que essa declaração foi proclamada. É para as mãos dos legisladores e todos 
os legisladores, e ninguém além dos legisladores, que as algemas que ela fornece são voltadas; é contra as intrusões apreendidas dos legisladores que os direitos em questão, a liberdade e a propriedade, e assim por diante, são tornados seguros. É contra essas intrusões, e danos e perigos, que qualquer segurança que eles professam ter diz respeito. Preciosa segurança para direitos ilimitados contra legisladores, se a extensão desses direitos, em qualquer direção, fosse de propósito deixada ao bel prazer desses mesmos legisladores!

Sem sentido ou inúteis, e, em ambos os casos, perniciosos, é a alternativa.

Basta para esses direitos pretensamente irrevogáveis como um todo: sua inconsistência uns com os outros, bem como a inconsistência deles, como direitos irrevogáveis, com a existência do governo e de uma sociedade pacífica, que vai aparecer ainda mais claramente quando os examinamos um a um.

1. Liberdade, então, é imprescritível - não pode ser tomada - está fora do poder de qualquer governo jamais retirar a liberdade, ou seja, todos os ramos da liberdade - cada exercício individual da liberdade; por que não há nenhum limite colocado - nenhuma distinção - nenhuma exceção feita. O que esses instrutores bem como governadores da humanidade parecem não saber é que todos os direitos são feitos às expensas da liberdade - todas as leis pelas quais os direitos são criados ou confirmados. Nenhum direito sem a correspondente obrigação. Liberdade, entendida como contra a coerção da lei, pode, é verdade, ser dada por uma simples retirada da obrigação pela qual aquela coerção foi aplicada - pela simples revogação da lei coercitiva. Mas entendida como contra a coerção aplicável de um indivíduo a outro indivíduo, nenhuma liberdade pode ser dada a um homem a não ser na proporção em que essa seja retirada de outro. Todas as leis coercitivas, portanto (ou seja, todas as leis a não ser as leis constitucionais e as leis revogando ou modificando leis coercitivas), e em particular todas as leis que criam liberdades são, não importa como sejam, revogadoras da liberdade. Não essa ou aquela lei apenas - não essa ou aquela lei possível, mas quase todas as leis, são, portanto, repugnantes a esses direitos naturais e imprescritíveis, consequentemente nulas e sem efeito, conclamando à resistência e à insurreição, e assim por diante, como antes.

Leis que criam direitos de propriedade são também atingidas pelo mesmo anátema. Como é dada a propriedade? Pela restrição da liberdade; ou seja, afastando-a tanto quanto necessário para o propósito. Como a sua casa torna-se sua? Ao se impedir qualquer outra pessoa de ter a liberdade de nela entrar sem a sua licença.

2. Propriedade. A propriedade aparece em segundo na lista, direitos de propriedade estão entre os direitos naturais e imprescritíveis do homem - os direitos que o homem não deve às leis, e que não podem ser retirados dele pelas leis. Os homens - isto é, todos os homens (pois uma expressão geral colocada sem exceção é uma expressão universal) tem o direito à propriedade, aos direitos de propriedade, um direito que não pode ser retirado deles pelas leis. Direitos de propriedade. Bom: mas em relação à qual objeto? pois falar em direitos de propriedade sem falar 
de um objeto ao qual eles se refiram - sem um objeto sobre o qual, ou em relação ao qual eles possam ser exercidos - torna-os sem muito valor, muito dificilmente eles valerão a pena serem cuidados, com tanta solenidade. Em vão teriam todas as leis do mundo assegurado que eu tenho direito a alguma coisa. Se isso é tudo que elas fizeram por mim - se não há algum objeto específico em relação ao qual meus direitos de propriedade sejam estabelecidos, eu devo pegar o que eu quero, sem direito, ou morrer de fome. Como não há esse objeto especificado com relação a cada homem, ou a qualquer homem (de fato, como poderia haver?) a inferência necessária (tomando a passagem literalmente) é que todo homem tem todos os direitos de propriedade com relação a todos os objetos passíveis de propriedade sem exceção: em uma palavra, que todo homem tem direito a tudo. Infelizmente, na maioria dos assuntos de propriedade, o que é direito de todos os homens é direito de nenhum homem; então o efeito dessa parte do oráculo, se observada, seria, não estabelecer a propriedade, mas extingui-la - torna-la impossível de ser jamais revivida: e esse é um dos direitos declarados imprescritíveis.

Provavelmente será reconhecido que, de acordo com essa construção, a cláusula em questão é igualmente ruinosa e absurda - e então a inferência pode ser que não era essa a construção, não era esse o sentido em vista. Mas, pela mesma regra, cada possível construção que as palavras empregadas podem admitir deve ser provada como não sendo o sentido em vista, bem como essa cláusula não é mais absurda ou ruinosa do que todas as que vieram antes dela, e uma boa dose do que vem depois dela. Em suma, se esse não é o significado, qual é? Dê-se-lhe um sentido - um sentido qualquer, ela é perniciosa - para salvá-la dessa imputação só há um caminho, que é reconhecer que é nonsense.

Então muito poderia ser clareado, se há algo de claro nisso, que de acordo com essa cláusula, quaisquer direitos de propriedade, qualquer propriedade que um homem tenha, não importa como, sendo imprescritível, não pode jamais ser retirada dele por qualquer lei, ou qual seria o uso ou o sentido dessa cláusula? Pois no momento em que é reconhecido com relação a qualquer coisa, que essa coisa é minha propriedade, não importa como ou quando veio a ser, naquele momento é reconhecido que isso nunca poderá ser retirado de mim: dessa forma, por exemplo, todas as leis e todos os julgamentos, por meio dos quais qualquer coisa é retirada de mim sem o meu livre consentimento - todos os impostos, por exemplo, e todas as multas são nulas, e, como tal, exigem resistência e insurreição, e assim por diante, como antes.

3. Segurança. Segurança é o terceiro nessa lista de direitos naturais e imprescritíveis, os quais as leis não dão, e os quais as leis não podem em qualquer grau tentarem retirar. Sob a égide da segurança, a liberdade poderia ter sido incluída, bem como a propriedade: uma vez que segurança para a liberdade, ou para o desfrute da liberdade, pode ser compreendido como um ramo da segurança: segurança para a propriedade, ou para o desfrute dos direitos de propriedade, também. A segurança para a pessoa é a vertente que parece estar em questão aqui: segurança para a pessoa de cada homem, contra todas as impressões dolorosas ou desagradáveis (excluídas 
aquelas que consistem no mero distúrbio do desfrute da liberdade) pelas quais um homem é afetado pessoalmente; perda da vida - perda dos membros - perda do uso dos membros - feridas, contusões e afins. Todas as leis são nulas e sem valor então, se de qualquer modo ou por qualquer razão exponham a pessoa de qualquer homem a qualquer risco - as que determinam a pena capital ou punições corporais, as que expõem o homem a riscos pessoais no serviço militar contra inimigos estrangeiros, ou as que estabelecem o poder judicial contra os delinquentes - todas as leis que, para preservar o país da peste, autorizam a execução imediata da pessoa suspeita, no caso em que ele ultrapasse certos limites.

4. Resistência à opressão. Quarto e último na lista dos direitos naturais e imprescritíveis, a resistência à opressão - significando, suponho, o direito a resistir à opressão. O que é opressão? Poder mal-aplicado em prejuízo de algum indivíduo. O que é que uma pessoa tem em vista quando fala de opressão? Algum exercício de poder que ele considera como indevido em prejuízo de algum indivíduo - que produz nesse indivíduo algum sofrimento ao qual (seja proibido pelas leis ou não) nós consideramos que ele não deveria ter sido sujeito. Mas contra tudo o que possa vir debaixo do nome de opressão, já foi feita provisão, do modo que vimos, pelo reconhecimento dos três direitos precedentes; uma vez que nenhuma opressão pode recair sobre um homem que não implique na infringência de seus direitos com relação à liberdade, seus direitos em relação à propriedade e seus direitos em relação à segurança, como anteriormente descrito. Onde, então, está a diferença? Qual é o propósito dessa quarta cláusula após as três primeiras? Esse é o propósito: o prejuízo que buscam prevenir e os direitos que que buscam estabelecer são os mesmos; a diferença reside na natureza do remédio que se pretende aplicar. Para apresentar o prejuízo em questão, o esforço das três primeiras cláusulas é atar as mãos do legislador e seus subordinados, pelo medo da nulidade, e a remota apreensão com a resistência geral e a insurreição. O objetivo dessa quarta cláusula é levantar a mão do indivíduo em questão para prevenir a infração deliberada de seus direitos no momento em que ele a considere prestes a acontecer.

Sempre que você estiver prestes a ser oprimido, você tem o direito de resistir à opressão: sempre que você se considere como a ser oprimido, considere que você tem o direito de oferecer resistência e a agir de acordo. Considerando-se qualquer lei de qualquer tipo - qualquer ato de poder, supremo ou subordinado, legislativo, administrativo ou judiciário, como desagradável a um homem, especialmente se, na consideração desse desagrado, sua opinião é que tal ato de poder não deveria ter sido exercido, a pessoa com certeza olha para ele como uma opressão: tanto quanto algo dessa natureza aconteça a um homem - tanto quanto algo aconteça a um homem que inflame as suas paixões - esse artigo, por temer que suas paixões não sejam suficientemente inflamadas por si mesmas, estabelece para si próprio o trabalho de soprar a chama, conclamando a pessoa à resistência. Não se submeta a nenhum decreto ou outro ato de poder, de justiça, se você não estiver perfeitamente convencido. Se um policial o convocar a servir na milícia, atire no policial e não no inimigo; - se o comandante de uma gangue da imprensa te atrapalha, jogue-o no mar - se um 
oficial de justiça, jogue-o pela janela. Se um juiz sentencia você a ser preso ou morto, tenha uma adaga às mãos e dê o primeiro golpe no juiz. 